\title{
Charcoal Canker of Pear, Plum, and Quince Trees Caused by Biscogniauxia rosacearum sp. nov. in Southern Italy
}

Maria Luisa Raimondo, Francesco Lops, and Antonia Carlucci, Department of Sciences, Agriculture, Food and the Environment, University of Foggia, 71121 Foggia, Italy

\begin{abstract}
Raimondo, M. L., Lops, F., and Carlucci, A. 2016. Charcoal canker of pear, plum, and quince trees caused by Biscogniauxia rosacearum sp. nov. in southern Italy. Plant Dis. 100:1813-1822.

The genus Biscogniauxia is paraphyletic to members of the family Xylariaceae and includes at least 52 species to date that are mainly pathogens of dicotyledonous angiosperm trees. Most of these are forest trees, such as those in the genera Acacia, Acer, Alnus, Eucalyptus, Fraxinus, Populus, and Quercus, and other species of minor importance. Biscogniauxia spp. have been reported as endophytes or secondary invaders that attack only stressed plants. During a survey in rosaceous orchards in southern Italy, several charcoal cankers were observed and stroma samples were

collected. A collection of 31 Biscogniauxia isolates was analyzed. Their phylogenetic relationships were determined through study of the internal transcribed spacer, $\beta$-tubulin, and actin gene sequences. Combining morphological, cultural, and molecular data, a new species of Biscogniauxia is described here as Biscogniauxia rosacearum. This new species was isolated for the first time from rosaceous hosts in Apulia. Pathogenicity tests showed that it causes symptoms on stems when artificially inoculated and produces stromata on the bark surface.
\end{abstract}

Biscogniauxia Kuntze in the family Xylariaceae (order Xylariales) had long been known as Nummularia Tul. \& C. Tul., until Miller (1961) placed most of its members in the section Applanata of Hypoxylon. A few years later, Pouzar $(1979,1986)$ and Ju et al. (1998) defined the current concept of the genus Biscogniauxia. This genus has been recorded worldwide, including in the United States (Gonzàlez and Rogers 1993; Rogers et al. 2008), Africa (Linnakoski et al. 2012; Mugambi et al. 2009), Asia (Whalley et al. 2012), and Europe (Cannon et al. 1985; Ragazzi 2009; Ragazzi et al. 2012; Rappaz 1995). At present, it includes at least 52 species (Ju and Rogers 2001; Ju et al. 1998; Mugambi et al. 2009; Rappaz 1995; Rogers et al. 2000, 2008; Vasilyeva and Stephenson 2007, 2010; Vasilyeva et al. 2012; Whalley et al. 1990, 2000) that are exclusively parasites of dicotyledonous angiosperm trees such as species of Acacia, Acer, Alnus, Artocarpus, Carya, Celtis, Coprosma, Eucalyptus, Fagus, Fraxinus, Gluta, Lithocarpus, Padus, Phyllirea, Pisonia, Populus, Psidium, Quercus, Rhamnus, Rubus, and Tilia (Ju and Rogers 2001; Ju et al. 1998; Mugambi et al. 2009; Rappaz 1995; Rogers et al. 2000, 2008; Vasilyeva and Stephenson 2007; Vasilyeva et al. 2012; Whalley et al. 2000).

The genus Biscogniauxia appears to be paraphyletic (Peláez et al. 2008; Sánchez-Ballesteros et al. 2000), with species of the closely related genera Camillea Fr. and Obolarina Pouzar clustered inside it (Pažoutová et al. 2010).

Species of Biscogniauxia such as Biscogniauxia mediterranea are known as the causal agents of charcoal cankers on oak trees. In Italy, $B$. mediterranea is the main species associated with the decay of oak trees, especially Quercus cerris, $Q$. robur, $Q$. frainetto, and $Q$. pubescens (Ragazzi et al. 1989; Vannini and Scarascia Mugnozza 1991; Vannini et al. 1996).

This pathogen has always been considered a secondary fungal invader that attacks only stressed or old hosts. It is thought that it can live as an endophyte in all of the aerial organs of oak trees (rarely in the leaves), and has a latent phase that does not result in any symptoms (Wilson 1995). However, it can act as an opportunistic pathogen when the host is weakened by abiotic or biotic factors such as prolonged

Corresponding author: A. Carlucci; E-mail: antonia.carlucci@unifg.it

Accepted for publication 25 April 2016.

http://dx.doi.org/10.1094/PDIS-09-15-1037-RE

C 2016 The American Phytopathological Society drought periods (Biocca and Motta 1995, Vannini and Scarascia Mugnozza 1991) or when attacked by other pathogens. Thus, these fungi are facultative saprophytes that spend most of their life cycle as parasites but can also persist for long periods on dead material (Nugent et al. 2005). B. mediterranea can rapidly colonize xylem and bark tissues to induce necrosis and canker formation, and to accelerate tree decline and eventually cause death (Desprez-Loustau et al. 2006; Linaldeddu et al. 2011). The great abundance of inoculum produced on colonized parts of a tree and the dispersal of ascospores either aerially or by insects is an important factor in the spread of this fungus in forests.

During a survey in fruit orchards throughout the Apulia region (southern Italy) from 2013 to 2014, cankers and unusual stromata were observed on the stems and branches surface of many fruit trees, including pear, plum, and quince, in Canosa di Puglia (Bari-AndriaTrani Province). A detailed phylogenetic study was performed to determine the correct taxonomic position of the fungi collected in this study. Therefore, the main objectives of the present study were to identify and characterize isolates of Biscogniauxia collected from pear, plum, and quince trees in southern Italy, as well as to demonstrate that they can cause disease symptoms on rosaceous hosts using pathogenicity assays.

\section{Materials and Methods}

Fungal isolates. During the summers of 2013 and 2014, several charcoal cankers were observed on the stems and branches of pear, plum, and quince trees of orchards in Canosa di Puglia (BariAndria-Trani) $\left(41^{\circ} 13^{\prime} 21.77^{\prime \prime} \mathrm{N}, 16^{\circ} 2^{\prime} 52.96^{\prime \prime} \mathrm{E}\right)$ in Apulia, southern Italy. The stromata observed were applanate and black and resembled those of Biscogniauxia spp. (Fig. 1). Representative samples of these charcoal cankers were collected from 62 symptomatic trees (33 from quince, 21 from pear, and 8 from plum) during the growth stage. The ages of the fruit trees varied from 13 to 20 years old. The samples were transported to the laboratory for analysis. A portion of the stromata was removed with a sterilized scalpel and surface sterilized (Fisher et al. 1992). The stromatal contents were scooped out and placed into a tube containing sterile distilled water; then, a sterile wire loop was used to spread $300 \mu$ l of this suspension on petri dishes containing $15 \mathrm{ml}$ of potato dextrose agar (PDA; 3.9\% potato dextrose agar; Oxoid Ltd.), which were then incubated at $23^{\circ} \mathrm{C}\left( \pm 2^{\circ} \mathrm{C}\right)$ in the dark. After 24 to $36 \mathrm{~h}$ of incubation, single germinating ascospores were transferred to fresh PDA plates. All fungal colonies that were morphologically similar to Biscogniauxia spp. were retained. Twenty-four strains of Biscogniauxia spp. are maintained in the culture collection 
of the Department of Science of Agriculture, Food and the Environment, of the University of Foggia (Italy), and the reference strains are in the collection of the Centraalbureau voor Schimmelcultures (CBS) Utrecht, The Netherlands. To compare the morphological and molecular differences, seven strains of Biscogniauxia spp. from $Q$. pubescens available from the collection of the abovementioned department, collected and maintained over the last 3 years from woods in two localities in the Apulia region that are in a national nature reserve: Incoronata (Foggia; 41 ${ }^{\circ} 23^{\prime} 29^{\prime \prime} \mathrm{N}, 15^{\circ} 39^{\prime} 35^{\prime \prime} \mathrm{E}$ ) and Accadia (Foggia; $41^{\circ} 10^{\prime} 00^{\prime \prime} \mathrm{N}, 15^{\circ} 20^{\prime} 00^{\prime \prime} \mathrm{E}$ ), were also included in this study.

Morphology. The Biscogniauxia asexual morphs were morphologically characterized on malt extract agar (MEA; 2\% malt extract [Oxoid Ltd.] and 1.5\% agar [Difco]), oat meal agar (OA; $30 \mathrm{~g}$ of oat, $8 \mathrm{~g}$ of Oxoid agar, and $1,000 \mathrm{ml}$ of water) (Crous et al. 2009), and PDA, with incubation at $25^{\circ} \mathrm{C}\left( \pm 2^{\circ} \mathrm{C}\right)$ in the dark for 2 weeks. Colony morphology and color were defined on MEA, OA, and PDA at $25^{\circ} \mathrm{C}\left( \pm 2^{\circ} \mathrm{C}\right)$ after 16 days, using the color charts of Rayner (1970). Cardinal temperatures for growth were determined by incubation of the PDA plates in the dark at temperatures of 5 to $40^{\circ} \mathrm{C}$ at $5^{\circ} \mathrm{C}$ intervals. Radial growth was measured on PDA plates after
8 days at $25^{\circ} \mathrm{C}\left( \pm 2^{\circ} \mathrm{C}\right)$. The macroscopic features of the stromata were determined under a stereomicroscope (Nikon SMZ 645) and photographs were taken with a digital camera (Nikon Coolpix P900). The microscopic features of the sexual morphs were determined directly from fresh stromata by dissecting perithecia from stromata and placing the contents in distilled water, methylene blue solution, lactic acid, and Lugol's solution. The microscopic features of asexual morphs were determined using the slide culture technique of Carlucci et al. (2012). The microscopic examination was under Normaski differential interference contrast optics (Leica DM5500 microscope) and the images were recorded with a digital camera (Leica DFC420). The dimensions and structures of the asci, ascospores, ascal apical ring, conidiophores, and conidia were determined in $100 \%$ lactic acid or Lugol's solution from 30 measurements made with a Leica LAS measurement module (Leica Microsystem $\mathrm{GmbH}$ ) from images recorded at $\times 40$ or $\times 100$ magnification. The 5th and 95th percentiles were defined for all of the measurements, with the extremes given in parentheses.

DNA isolation and polymerase chain reaction amplification. Genomic DNA of all of the isolates was extracted according to Carlucci et al. (2013). The 5.8S rDNA gene and flanking internal
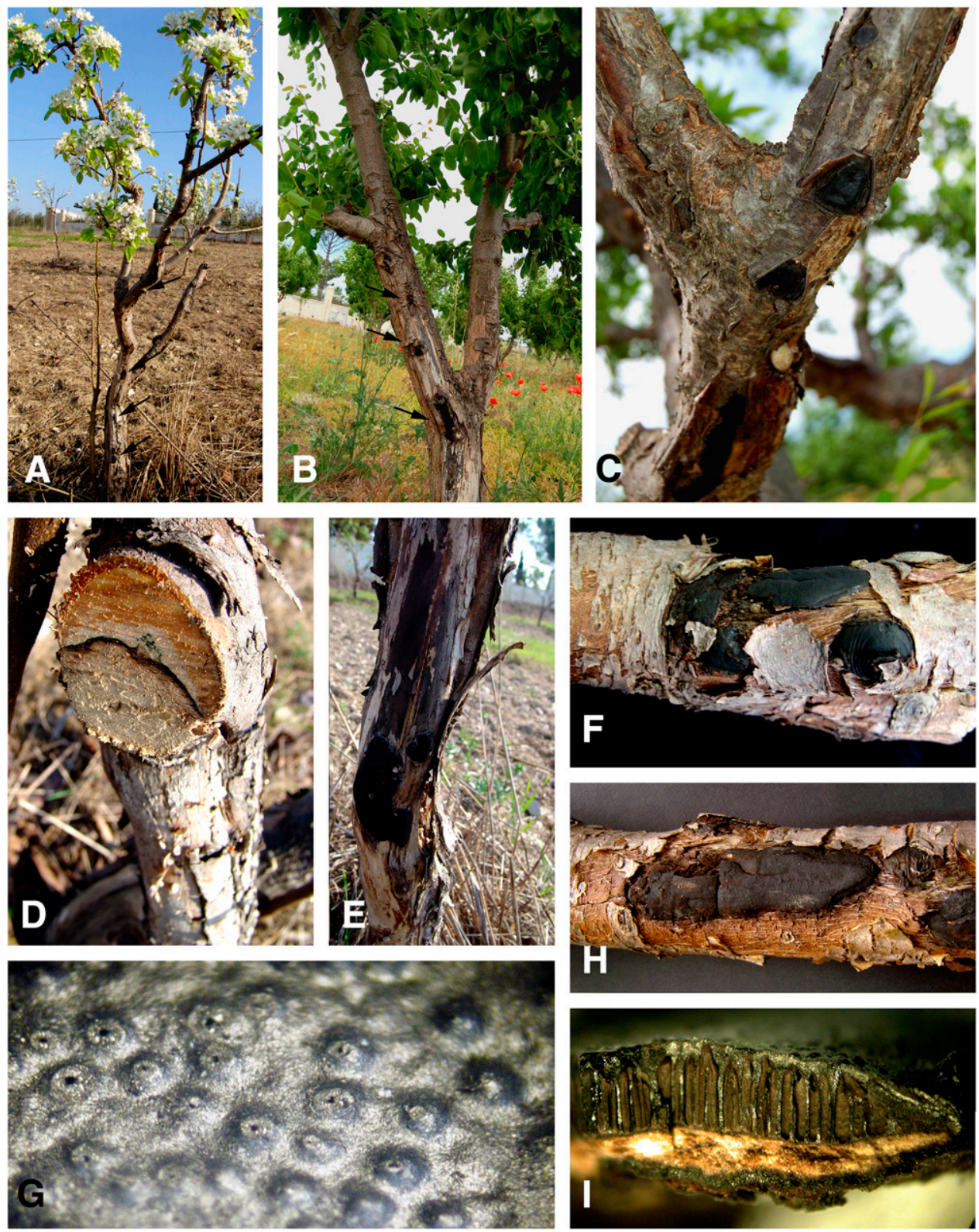

Fig. 1. A to C, Disease symptoms and charcoal stromata on quince, plum, and pear trees, respectively (black arrows). D, Dead wood in cross-section of pear branch corresponding to charcoal stromata. E to G, Stromata on trunk and branch bark of Rosaceae hosts. H, View of the stromatal surface. I, Section through the stroma, showing perithecia. 
transcribed spacer (ITS) regions, the partial $\beta$-tubulin gene (TUB), and the partial actin gene (ACT) were amplified and sequenced using the primer pairs ITS1 and ITS4 (White et al. 1990), T1 (O'Donnell and Cigelnik 1997) and Bt2b (Glass and Donaldson 1995), and ACT-512F and ACT-783R (Carbone and Kohn 1999), respectively, with all primer pairs supplied by Eurofins Italy service. Polymerase chain reactions (PCR) were performed in an S1000 thermal cycler (Bio-Rad). The ITS amplifications were according to Carlucci et al. (2012). The TUB and ACT amplifications were according to Raimondo et al. (2014). The amplification products were verified by agarose gel electrophoresis. The amplified PCR fragments were purified with NucleoSpin extract II purification kits (Macherey-Nagel) before DNA sequencing. The two strands of the PCR products were sequenced by the Eurofins Italy service.

Phylogenetic analysis. Nucleotide sequences were edited with BioEdit v.7.0.9 (http://www.mbio.ncsu.edu/BioEdit). The ITS and TUB/ACT datasets comprised sequences of closely related Biscogniauxia spp. selected in BLAST searches in GenBank. The ITS sequences were aligned with ClustalX v. 1.83 (Thompson et al. 1997). Alignment gaps were treated as fifth character, and all of the characters were unordered and of equal weight. Maximumparsimony analysis was performed with PAUP v. $4.0 \mathrm{~b} 10$ (Swofford 2003) using the heuristic search option, with 1,000 random taxa additions and tree bisection and reconstruction as the branch swapping algorithm. Branches of zero length were collapsed, and all multiple, equally parsimonious trees were saved. Bootstrap support values were calculated from 1,000 heuristic search replicates and 100 random taxon additions. The tree length (TL), consistency index (CI), retention index (RI), rescaled consistency index (RC), and homoplasy index $(\mathrm{HI})$, were calculated and the resulting trees were visualized with TreeView, v. 1.6.6 (Page 1996).

The TUB and ACT sequences were combined and aligned with ClustalX v. 1.83 (Thompson et al. 1997). A partition homogeneity test of the TUB/ACT alignment was conducted with PAUP v. $4.0 \mathrm{~b} 10$ (Swofford 2003) to test pairwise congruence between the sequence datasets. Phylogenetic analysis was performed as described above but with treatment of the gaps as missing data. Newly generated sequences were deposited in GenBank (Table 1), the alignment and trees were deposited in TreeBase (www.treebase.org), and the taxonomic novelties were deposited in MycoBank (www.mycobank. org) (Crous et al. 2004). Annulohypoxylon cohaerens (strain BCRC34013; GenBank ITS $=$ EF026140, TUB $=$ AY951655, and ACT = AY951766) and Hypoxylon rubiginosum (strain BCRC34116; GenBank ITS = $\mathrm{EF026143,} \mathrm{TUB}=\mathrm{AY} 951751$, and ACT $=$ AY951862) were used as outgroups in the phylogenetic analysis of ITS and TUB/ACT sequences.

Pathogenicity tests. Four isolates of B. rosacearum $(\mathrm{B} \times 25$, Bx26, $\mathrm{Bx} 28$, and $\mathrm{Bx} 29$ from Q. pubescens, Prunus domestica, Cydonia oblonga, and Pyrus communis, respectively) were used in the pathogenicity tests, which were carried out in September 2013 on wood stems (diameter $=3$ to $5 \mathrm{~cm}$ ) of about 15 - to 20 -year-old pear, plum, and quince trees in open fields in orchards in Canosa di Puglia (average temperature was $24^{\circ} \mathrm{C}$ and relative humidity was $66 \%$ ). The bark of the wood stems was removed from a surface about $10 \mathrm{~cm}$ long and 3 to $4 \mathrm{~cm}$ wide, using a sterilized scalpel. A suspension of $1 \times 10^{6}$ ascospores $/ \mathrm{ml}(5 \mathrm{ml})$ was sprayed on this wound. After inoculation, the wounds were wrapped with wet, sterile cotton wool and sealed with Parafilm for about 10 days. Controls were mock inoculated with sterile distilled water. Each experiment included 10 replicates per host and per isolate. The inoculated wood stems were examined every 4 months until May 2015. The leaf growth on the inoculated stems and stroma appearance and size on wood stems were assessed to fulfill Koch's postulates.

Statistical analyses were performed using Statistica (version 6; StatSoft). To test whether the data followed normal distributions, a Shapiro-Wilk test was used. The homogeneity of variance was assessed using Levene tests. Factorial analysis of variance (ANOVA) was performed to determine the significance of the B. rosacearum isolates on the plant hosts inoculated and to detect any interaction between these factors (plant host-isolate). One-way ANOVA was performed to evaluate the significant differences in percentages of stromata produced on stems inoculated by each $B$. rosacearum isolates and any difference due to plant host (pear, plum, and quince). Fischer's tests was used for the comparison of the treatment means at $P<0.01$.

\section{Results}

Phylogenetic analysis. The ITS sequences generated for the 31 isolates studied (Table 1) were aligned with 36 sequences retrieved from GenBank, which represented closely related species of Biscogniauxia. The dataset consisted of 67 taxa, which included A. cohaerens (EF026140) and H. rubiginosum (EF026143) as outgroups. After alignment and exclusion of incomplete portions at either end, the ITS dataset consisted of 783 characters (including alignment gaps). Of the 783 characters, 219 were constant, whereas 124 were variable and parsimony uninformative. Maximum-parsimony analysis of the remaining 440 parsimony-informative characters resulted in one most-parsimonious tree $(\mathrm{TL}=2,323, \mathrm{CI}=0.513, \mathrm{RI}=$ $0.724, \mathrm{RC}=0.371$, and $\mathrm{HI}=0.487$; TreeBase S17923). The phylogenetic tree showed two different clades of $B$. mediterranea with bootstrap values of $100 \%$ (Fig. 2). In particular, 26 isolates sequenced in this study matched 16 sequences of those available in the GenBank as B. mediterranea in clade 1, whereas the other 5 sequences matched the 5 sequences retrieved from the GenBank as $B$. mediterranea in clade 2 . The last clade included the sequence of a specimen examined and described as $B$. mediterranea (Candoussau, F. 366) from Ju et al. (1998).

The partition homogeny test on the TUB/ACT alignments of Biscogniauxia produced $P$ values of 0.120 , which indicated that the datasets were congruent and could be combined. TUB/ACT sequences were generated for 31 isolates and aligned with 22 sequences retrieved from GenBank. The dataset consisted of 53 taxa, including the two outgroup taxa A. cohaerens $(\mathrm{TUB}=\mathrm{AY} 951655$ and $\mathrm{ACT}=\mathrm{AY951766})$ and $H$. rubiginosum $(\mathrm{TUB}=\mathrm{AY} 951751$ and $\mathrm{ACT}=\mathrm{AY951862})$. After alignment and exclusion of incomplete portions at either end, the dataset consisted of 1,371 characters (including alignment gaps). Of the 1,371 characters, 533 were constant, whereas 163 were variable and parsimony uninformative. Maximum-parsimony analysis of the remaining 675 parsimony-informative characters resulted in five mostparsimonious trees $(\mathrm{TL}=2432, \mathrm{CI}=0.595, \mathrm{RI}=0.689, \mathrm{RC}=0.410$, and $\mathrm{HI}=0.405$; TreeBase $\mathrm{S} 17924)$. The phylogenetic tree shows a topology similar to that of the ITS tree (Fig. 3).

Taxonomy. The phylogenetic tree from the ITS analyses (Fig. 3) showed 25 species resolved, of which 2 species belong to the genus Camillea (Camillea tinctor and C. obularia), 2 belong to Obolarina (Obolarina dryophila and O. persica), 1 belongs to Theissenia (Theissenia cinerea), 1 belongs to Durotheca (Durotheca rogersii), and 19 belong to Biscogniauxia. Because both of the phylogenetic trees clearly showed two distinct clades that included sequences named as $B$. mediterranea, we considered that clade 2 is really related to $B$. mediterranea species, because the specimen examined as B. mediterranea (Candoussau, F. 366) (Ju et al. 1998) was in this clade. Instead, clade 1 included a novel species described here.

Biscogniauxia rosacearum A. Carlucci \& M. L. Raimondo, sp. nov. MycoBank MB816045 (Fig. 4).

Etymology. Named after the hosts, which belong to the family Rosaceae, from which this species was isolated for the first time.

Stromata. Erumpent through bark, applanate, irregularly ovate in outline, 10 to $90-\mathrm{mm}$ long, 10 to $20 \mathrm{~mm}$ wide, and 0.5 to $1.5 \mathrm{~mm}$ thick, with blackish mature surface. Carbonaceous tissues immediately beneath surface and between perithecia, grayish to blackish, coriaceous. The tissue below the perithecial layer of about $50-\mu \mathrm{m}$ thickness, grayish to blackish, coriaceous, persistent.

Perithecia. Dark brown, tubular, monostichous, minute, 0.18 to $0.24 \mathrm{~mm}$ in diameter, 0.6 to $1 \mathrm{~mm}$ high, with carbonaceous stromatal material surrounding individual perithecia.

Ostioles. $40 \mu \mathrm{m}$ in diameter, papillate, with punctate ostiolar openings, encircled with a disc of 0.2 to $0.3 \mathrm{~mm}$ in diameter formed by dehiscence of surrounding tissue. 
Table 1. Fungal cultures and specimens used in the present phylogenetic study

\begin{tabular}{|c|c|c|c|c|c|c|}
\hline \multirow[b]{2}{*}{ Species, cultures ${ }^{v}$} & \multirow[b]{2}{*}{ Host } & \multirow[b]{2}{*}{ Location } & \multirow[b]{2}{*}{ Collector } & \multicolumn{3}{|c|}{ GenBank accession numbers ${ }^{u}$} \\
\hline & & & & ITS & $\beta$-TUB & ACT \\
\hline \multicolumn{7}{|c|}{ Annulohypoxylon cohaerens } \\
\hline YMJ 310 & Fagus sp. & France, Ariege & J. Fournier & EF026140 & AY951655 & AY951766 \\
\hline \multicolumn{7}{|l|}{ Biscogniauxia anceps } \\
\hline YMJ 123 & Corylus avellana & France, Landes & $\ldots$ & EF026132 & AY951671 & AY951783 \\
\hline \multicolumn{7}{|l|}{ B. arima } \\
\hline YMJ $122^{w}$ & Wood & Mexico, San Luis Potosi State & F. San Martin. & EF026150 & AY951672 & AY951784 \\
\hline \multicolumn{7}{|l|}{ B. atropunctata } \\
\hline YMJ 128 & Wood & United States, North Carolina & L. F. Grand & JX507799 & AY951673 & AY951785 \\
\hline \multicolumn{7}{|l|}{ B. atropunctata } \\
\hline 9201 & Juniperus virginiana & United States & M. Hoffman & EF419906 & $\ldots$ & $\ldots$ \\
\hline \multicolumn{7}{|c|}{ B. atropunctata var. intermedia } \\
\hline ATCC38987 & $\ldots$ & United States & $\ldots$ & AF201705 & $\ldots$ & $\ldots$ \\
\hline B70M & Quercus sp. & Costa Rica & $\ldots$ & AJ390412 & $\ldots$ & $\ldots$ \\
\hline \multicolumn{7}{|l|}{ B. bartholomaei } \\
\hline ATCC 38992 & Wood & Russia & L. N. Vasilyeva & AF201719 & $\ldots$ & $\ldots$ \\
\hline \multicolumn{7}{|l|}{ B. capnodes } \\
\hline YMJ 138 & Corticated wood & Taiwan, Taipei & $\ldots$ & EF026131 & AY951675 & AY951787 \\
\hline \multicolumn{7}{|l|}{ B. citriformis } \\
\hline YMJ 88113012 & Wood & Taiwan & $\begin{array}{r}\text { Y.-M. Ju and } \\
\text { H. M. Hsieh }\end{array}$ & JX507800 & AY951677 & AY951790 \\
\hline YMJ 129 & Casuarina equisetifolia & United States & J. D. Rogers & JX507801 & AY951678 & AY951789 \\
\hline \multicolumn{7}{|l|}{ B. cylindrispora } \\
\hline YMJ $89092701^{x}$ & Bark of Cinnamomum & Taiwan, Taipei & $\cdots$ & EF026133 & AY951679 & AY951791 \\
\hline \multicolumn{7}{|l|}{ B. formosana } \\
\hline YMJ $8903220^{x}$ & Bark & Taiwan, Taipei & Y.-M. Ju & JX507802 & AY951680 & AY951792 \\
\hline B. granmoi & & & & & & \\
\hline YMJ 135 & Bark of Prunus padus & Austria, Steiermark & $\begin{array}{l}\text { W. Maurer and } \\
\text { C. Scheuer }\end{array}$ & JX507803 & AY951681 & AY951793 \\
\hline B. latirima & & & & & & \\
\hline YMJ 90080703 & Bark & Taiwan, Tai-tung County & $\ldots$ & EF026135 & AY951683 & AY951795 \\
\hline B. marginata & & & & & & \\
\hline MFLUCC 12-0740 & $\ldots$ & France & A. Gardiennet & KJ958407 & $\ldots$ & $\cdots$ \\
\hline ATCC 62608 & Quercus sp. & Pennsylvania & $\cdots$ & AJ390417 & $\ldots$ & $\cdots$ \\
\hline B. mediterranea & & & & & & \\
\hline $\begin{array}{l}\text { Candoussau, F. } 366 \text {, } \\
\text { YMJ 147y }\end{array}$ & $\begin{array}{l}\text { Corticated wood } \\
\text { of Fagus sp. }\end{array}$ & France, Oloron & F. Candoussau & EF026134 & AY951684 & AY951796 \\
\hline CBS 280.61 & $\ldots$ & United States & $\ldots$ & AJ390413 & $\ldots$ & $\cdots$ \\
\hline Ohu 19B & Stem of Opuntia humifusa & United States & $\ldots$ & KF850388 & $\ldots$ & $\ldots$ \\
\hline EPU38CA & Echinacea purpurea & United States & C. R. Carvalho & KP127979 & $\ldots$ & $\ldots$ \\
\hline G410 & Silybum marianum & United States & $\ldots$ & KM215652 & $\ldots$ & $\ldots$ \\
\hline Bx63 & Quercus pubescens & Italy, Apulia, Accadia & F. Lops & KT253501 & KT253535 & KT253504 \\
\hline Bx69 & $Q$. pubescens & Italy, Apulia, Accadia & F. Lops & $\ldots$ & $\ldots$ & $\ldots$ \\
\hline Bx70 & Q. pubescens & Italy, Apulia, Incoronata & A. Carlucci & KT253502 & KT253536 & KT253505 \\
\hline Bx83 & Q. pubescens & Italy, Apulia, Accadia & M. L. Raimondo & $\ldots$ & $\ldots$ & $\ldots$ \\
\hline Bx85 & Q. pubescens & Italy, Apulia, Incoronata & A. Carlucci & KT253503 & KT253537 & KT253506 \\
\hline B. nummularia & & & & & & \\
\hline CBS969.70 & Fagus sylvatica & England & $\ldots$ & AJ390415 & $\ldots$ & $\ldots$ \\
\hline B.NUMM3 & $\ldots$ & Italy & A. Mazzaglia & AJ246231 & $\ldots$ & $\ldots$ \\
\hline H86 & Inner bark of Salix alba & Slovakia, Jursky Sur & P. Srutka & GQ428318 & GQ428324 & GQ428312 \\
\hline MUCL 51395 & Fagus sp. & France & $\cdots$ & JX658444 & $\ldots$ & $\cdots$ \\
\hline B. philippinensis var. mic & & & & & & \\
\hline YMJ 89041101 & Bark & Taiwan & $\ldots$ & EF026136 & AY951685 & AY951797 \\
\hline B. repanda & & & & & & \\
\hline ATCC 62606 & $\cdots$ & $\cdots$ & $\cdots$ & AJ390418 & $\cdots$ & $\cdots$ \\
\hline B. rosacearum & & & & & & \\
\hline CFB993 & Q. ilex & Spain & $\ldots$ & AF250624 & $\ldots$ & $\ldots$ \\
\hline JC55 & Q. ilex & Spain & $\ldots$ & AF280625 & $\ldots$ & $\ldots$ \\
\hline JC809 & Q. ilex & Spain & $\ldots$ & AF326479 & $\ldots$ & $\ldots$ \\
\hline JC2640 & Q. ilex & Spain & $\ldots$ & AF326482 & $\ldots$ & $\ldots$ \\
\hline $2 \mathrm{C} 7$ & $\cdots$ & Italy & A. Mazzaglia & $\mathrm{AJ} 246222$ & $\ldots$ & $\ldots$ \\
\hline & & & & & (continues & n next page) \\
\hline
\end{tabular}

u ITS = internal transcribed spacer, TUB $=\beta$-tubulin, and ACT = actin.

$\checkmark$ Isolates studied are indicated in bold.

w Isotype.

$\mathrm{x}$ Holotype.

y Specimen examined by Ju et al. (1998)

z Ex-type. 
Table 1. (continued from preceding page)

\begin{tabular}{|c|c|c|c|c|c|c|}
\hline \multirow[b]{2}{*}{ Species, cultures ${ }^{v}$} & \multirow[b]{2}{*}{ Host } & \multirow[b]{2}{*}{ Location } & \multirow[b]{2}{*}{ Collector } & \multicolumn{3}{|c|}{ GenBank accession numbers ${ }^{u}$} \\
\hline & & & & ITS & $\beta$-TUB & ACT \\
\hline 3961 & Holcus lanatus & Spain & $\ldots$ & FN394711 & $\ldots$ & $\ldots$ \\
\hline PC05.008 & Platypus cylindrus & Portugal, Alentejo & $\ldots$ & FR734186 & $\ldots$ & $\ldots$ \\
\hline ВM07.003 & P. cylindrus & Portugal, Alentejo & $\ldots$ & FR734187 & $\ldots$ & $\ldots$ \\
\hline CPC 18215 & Q. castaneifolia & Iran & $\ldots$ & JF295127 & $\ldots$ & $\ldots$ \\
\hline CPC 18216 & Q. castaneifolia & Iran & $\ldots$ & JF295128 & $\ldots$ & $\ldots$ \\
\hline CPC 18217 & Q. castaneifolia & Iran & $\ldots$ & JF295129 & $\ldots$ & $\ldots$ \\
\hline A06A & Arthropods & Portugal & $\ldots$ & JQ781705 & $\ldots$ & $\ldots$ \\
\hline A06D & Arthropods & Portugal & $\ldots$ & JQ781708 & $\ldots$ & $\ldots$ \\
\hline $\mathrm{A} 06 \mathrm{E}$ & Arthropods & Portugal & $\ldots$ & JQ781709 & $\ldots$ & $\ldots$ \\
\hline A60A & Arthropods & Portugal & $\ldots$ & JQ781799 & $\ldots$ & $\ldots$ \\
\hline ASR_H74_10A & Pinus sylvestris & Spain & $\ldots$ & JX421711 & $\ldots$ & $\ldots$ \\
\hline Bx1 & Pyrus communis & Italy, Apulia, Canosa di Puglia & F. Lops & KT253495 & KT253529 & KT253515 \\
\hline Bx3 & Cydonia oblonga & Italy, Apulia, Canosa di Puglia & F. Lops & KT253487 & KT253521 & KT253507 \\
\hline Bx4 & Prunus domestica & Italy, Apulia, Canosa di Puglia & F. Lops & KT253491 & KT253525 & KT253511 \\
\hline Bx5 & Pyrus communis & Italy, Apulia, Canosa di Puglia & M. L. Raimondo & $\ldots$ & $\ldots$ & $\ldots$ \\
\hline Bx6 & C. oblonga & Italy, Apulia, Canosa di Puglia & F. Lops & $\ldots$ & $\ldots$ & $\ldots$ \\
\hline Bx9 & Prunus domestica & Italy, Apulia, Canosa di Puglia & F. Lops & $\ldots$ & $\ldots$ & $\ldots$ \\
\hline Bx10 & Pyrus communis & Italy, Apulia, Canosa di Puglia & F. Lops & KT253496 & KT253530 & KT253516 \\
\hline Bx13 & P. communis & Italy, Apulia, Canosa di Puglia & A. Carlucci & $\ldots$ & $\ldots$ & $\ldots$ \\
\hline Bx14 & C. oblonga & Italy, Apulia, Canosa di Puglia & M. L. Raimondo & KT253488 & KT253522 & KT253508 \\
\hline Bx15 & C. oblonga & Italy, Apulia, Canosa di Puglia & A. Carlucci & $\ldots$ & $\ldots$ & $\ldots$ \\
\hline Bx17 & C. oblonga & Italy, Apulia, Canosa di Puglia & M. L. Raimondo & $\ldots$ & $\ldots$ & $\ldots$ \\
\hline Bx18 & Prunus domestica & Italy, Apulia, Canosa di Puglia & A. Carlucci & KT253492 & KT253526 & KT253512 \\
\hline Bx19 & C. oblonga & Italy, Apulia, Canosa di Puglia & F. Lops & KT253489 & KT253523 & KT253509 \\
\hline Bx22 & P. domestica & Italy, Apulia, Canosa di Puglia & F. Lops & $\ldots$ & $\ldots$ & $\ldots$ \\
\hline Bx24 & Pyrus communis & Italy, Apulia, Canosa di Puglia & A. Carlucci & $\ldots$ & $\ldots$ & $\ldots$ \\
\hline Bx25 & Q. pubescens & Italy, Apulia, Incoronata & F. Lops & KT253499 & KT253533 & KT253519 \\
\hline Bx26, CBS 141046 & Prunus domestica & Italy, Apulia, Canosa di Puglia & A. Carlucci & KT253493 & KT253527 & KT253513 \\
\hline Bx27 & Pyrus communis & Italy, Apulia, Canosa di Puglia & A. Carlucci & $\ldots$ & $\ldots$ & $\ldots$ \\
\hline Bx28, CBS 141002 & C. oblonga & Italy, Apulia, Canosa di Puglia & A. Carlucci & KT253490 & KT253524 & KT253510 \\
\hline Bx29 & P. communis & Italy, Apulia, Canosa di Puglia & A. Carlucci & KT253497 & KT253531 & KT253517 \\
\hline Bx30 & C. oblonga & Italy, Apulia, Canosa di Puglia & F. Lops & $\ldots$ & $\ldots$ & $\ldots$ \\
\hline Bx31 & Prunus domestica & Italy, Apulia, Canosa di Puglia & F. Lops & $\ldots$ & $\ldots$ & $\ldots$ \\
\hline Bx39 & P. domestica & Italy, Apulia, Canosa di Puglia & F. Lops & $\ldots$ & $\ldots$ & $\ldots$ \\
\hline Bx40 & Pyrus communis & Italy, Apulia, Canosa di Puglia & F. Lops & KT253498 & KT253532 & KT253518 \\
\hline Bx52 & Prunus domestica & Italy, Apulia, Canosa di Puglia & F. Lops & KT253494 & KT253528 & KT253514 \\
\hline Bx55 & Q.pubescens & Italy, Apulia, Accadia & A. Carlucci & KT253500 & KT253534 & KT253520 \\
\hline \multicolumn{7}{|l|}{ B. simplicior } \\
\hline YMJ 136 & $\begin{array}{l}\text { Wood of Rhamnus } \\
\text { cathartica }\end{array}$ & France, Roquebrune Montseron & $\ldots$ & EF026130 & AY951686 & AY951798 \\
\hline \multicolumn{7}{|l|}{ Biscogniauxia sp. } \\
\hline PP103 & Hevea brasiliensis & Peru & $\ldots$ & FJ884075 & $\ldots$ & $\ldots$ \\
\hline VegaE4-39 & Coffea arabica & United States, Hawaii & $\ldots$ & EU009960 & $\ldots$ & $\ldots$ \\
\hline SUT290 & $\ldots$ & Thailand & $\ldots$ & DQ322095 & $\ldots$ & $\ldots$ \\
\hline \multicolumn{7}{|l|}{ B. uniapiculata } \\
\hline YMJ 90080608 & Bark & Taiwan, Tai-tung & $\begin{array}{c}\text { Y.-M. Ju and } \\
\text { H. M. Hsieh }\end{array}$ & JX507805 & AY951687 & AY951799 \\
\hline \multicolumn{7}{|l|}{ Camillea obularia } \\
\hline ATCC 28093 & Rotten wood & Puerto Rico & $\ldots$ & AJ390423 & $\ldots$ & $\ldots$ \\
\hline \multicolumn{7}{|l|}{ C. tinctor } \\
\hline CBS 203.56 & Sassafras sp. & United States & $\ldots$ & AJ390421 & $\ldots$ & $\ldots$ \\
\hline SUT260 & $\ldots$ & Thailand & $\ldots$ & DQ322082 & $\ldots$ & $\ldots$ \\
\hline YMJ 363 & Dead wood & Martinique & C. Lechat & JX507806 & JX507795 & JX507797 \\
\hline \multicolumn{7}{|l|}{ Durotheca rogersii } \\
\hline YMJ $92031201^{x}$ & $\begin{array}{l}\text { Trunk of Machilus } \\
\text { zuihoensis }\end{array}$ & Taiwan, Nan-Tou & $\begin{array}{l}\text { Ju Y.-M. and } \\
\text { H. M. Hsieh }\end{array}$ & EF026127 & EF025612 & EF025597 \\
\hline \multicolumn{7}{|l|}{ Hypoxylon rubiginosum } \\
\hline YMJ 24 & Wood of Fraxinus & United Kingdom, North Wales & $\ldots$ & EF026143 & AY951751 & AY951862 \\
\hline \multicolumn{7}{|l|}{ Obolarina dryophila } \\
\hline H76 & Inner bark of Salix alba & Slovakia, Jursky Sur & Petr Srutka & GQ428317 & GQ428323 & GQ428311 \\
\hline \multicolumn{7}{|l|}{ O. persica } \\
\hline YMJ $1461^{x}$ & Dying $Q$. brantii & Iran & M. Mirabolfathy & JX507807 & JX507796 & JX507798 \\
\hline Theissenia cinerea & & & & & & \\
\hline YMJ 90071615 & Wood stump & Taiwan & $\begin{array}{l}\text { H. M. Hsieh and } \\
\text { Y.-M. Ju }\end{array}$ & EF026128 & EF025613 & EF025598 \\
\hline
\end{tabular}


Paraphyses. Filiform, tapering, sparsely septate, with oily contents, about $1.5 \mu \mathrm{m}$ in diameter near the base and about $1.1 \mu \mathrm{m}$ in diameter near the apex.

Asci. Eight-spored, cylindrical, arranged in uniseriate manner, short stipitates, with oily contents, (78.9-) 88.8 to 94.2 (-109.1) (mean, 91.5) $\mu \mathrm{m}$ long and (5.1-) 6.4 to $6.9(-8.6)$ (mean, 6.7) $\mu \mathrm{m}$ wide, with spore-bearing parts 79.2 to $85.0 \mu \mathrm{m}$ long, the stipes 7 to $12 \mu \mathrm{m}$ long, with apical ring clearly bluing in Lugol's iodine reagent, discoid, $1.4 \mu \mathrm{m}$ long and $2.6 \mu \mathrm{m}$ wide.

Ascospores. Brown to dark brown, unicellular in both mature and immature ascospores, nearly equilateral, with broadly rounded ends, smooth, (8.0-) 9.2 to 9.8 (-11.2) (mean, 9.5) $\mu \mathrm{m}$ long and (4.0-) 5.0

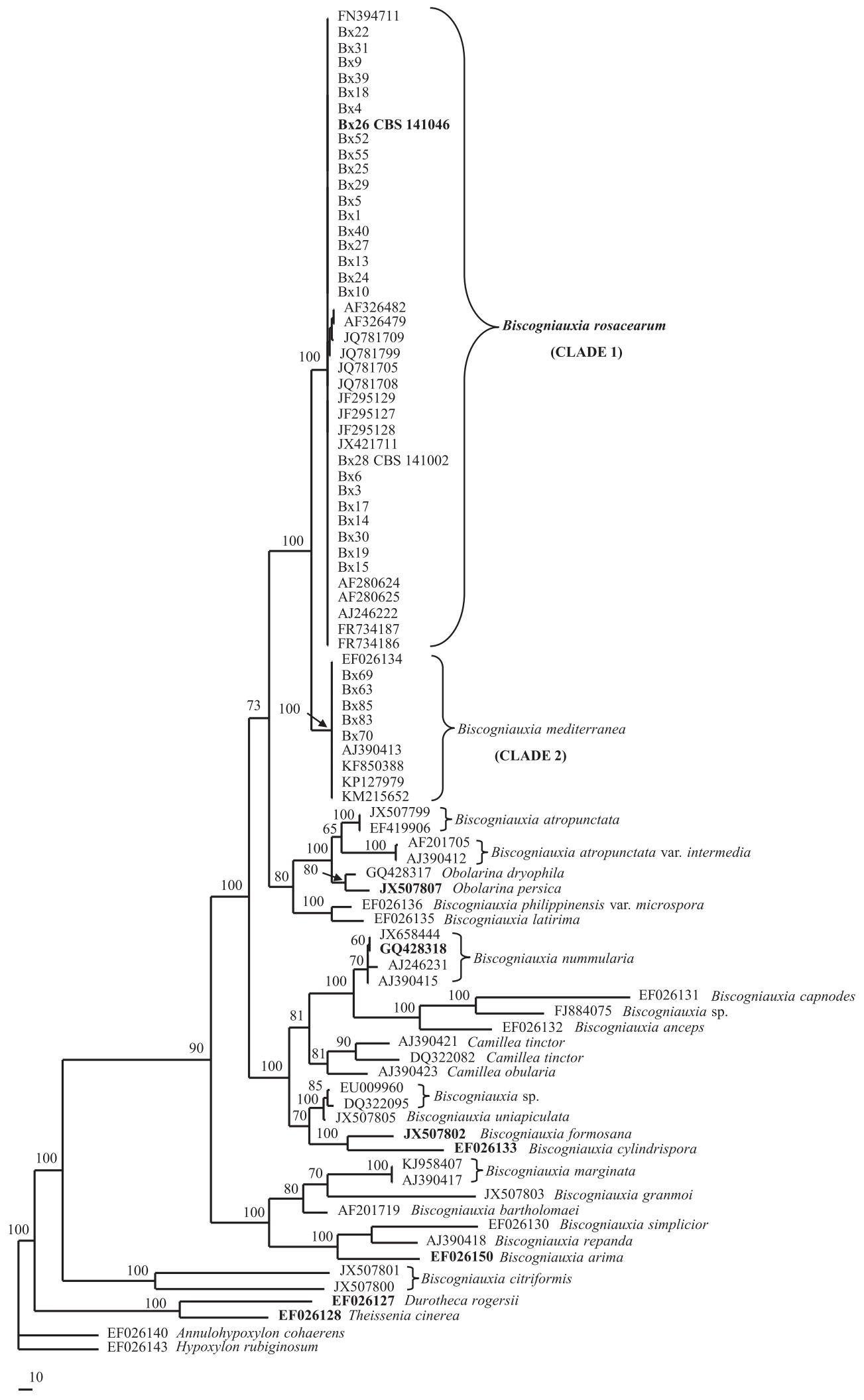

Fig. 2. Most parsimonious tree obtained from internal transcribed spacer alignment with bootstrap values from 1,000 replicates shown at the internodes. Ex-type sequences are highlighted in bold. Annulohypoxylon cohaerens and Hypoxylon rubiginosum were included as outgroups. 
to $5.4(-6.3)$ (mean, 5.2) $\mu \mathrm{m}$ wide, enveloped by a hyaline sheath. Germ slit straight, parallel to the long axis of the spore, almost full spore length.

Mycelia. Consisting of branched and septate hyphae, smooth to finely roughened, subhyaline to yellowish, occurring singly or in bundles of up to six, forming hyphal coils.
Conidiogenous structure. With Nodulisporium-like branching pattern, as defined by Ju and Rogers (1996).

Conidiophores. Hyaline to brownish, smooth to finely roughened, dichotomously branched, with two or three, and sometimes more, conidiogenous cells on each terminus.

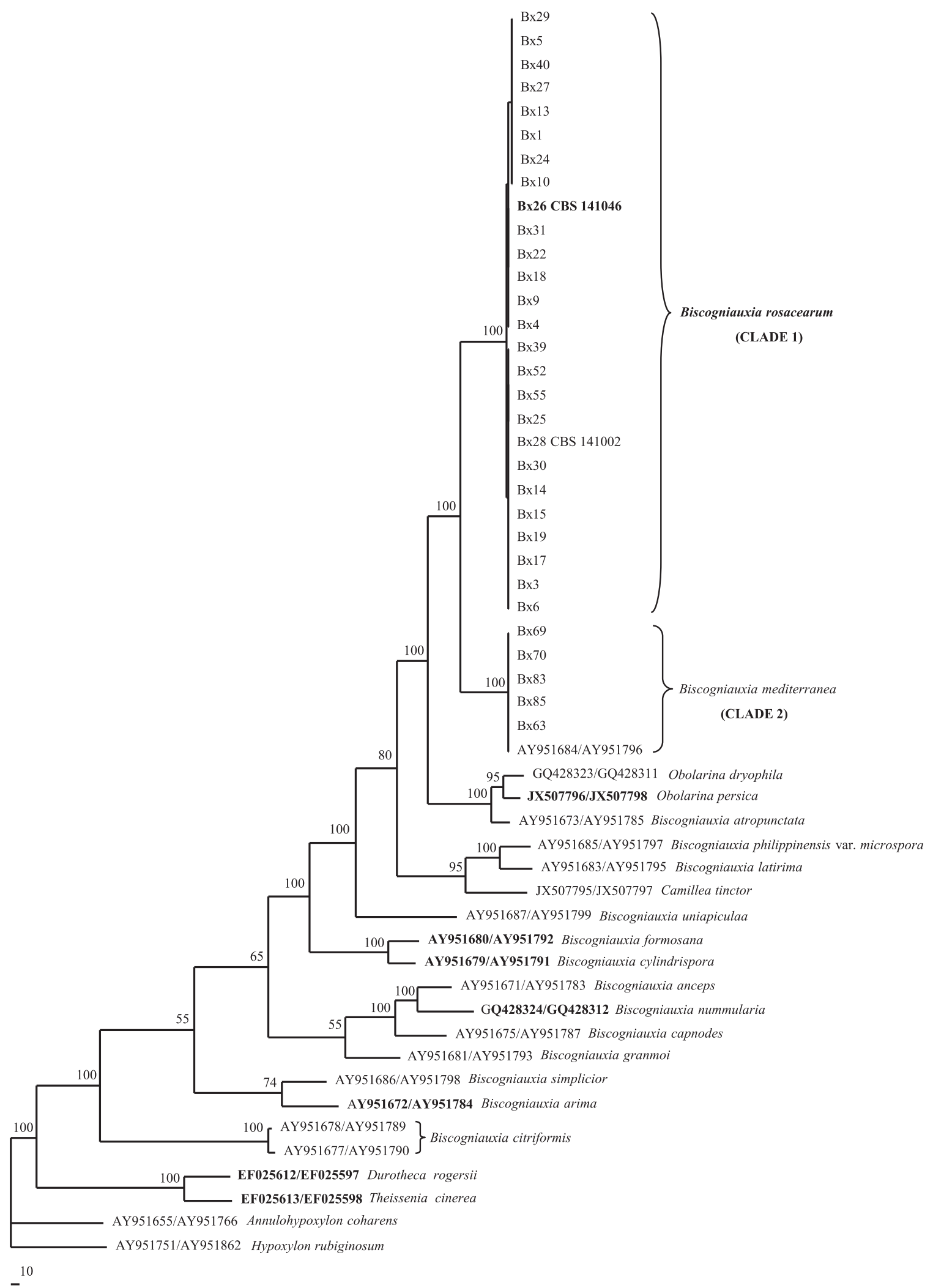

Fig. 3. One of the five most parsimonious trees obtained from the combined alignment of the partial $\beta$-tubulin/partial actin (TUB/ACT) gene sequence data, with bootstrap values from 1,000 replicates shown at the internodes. Accession numbers of the sequences obtained from the GenBank nucleotide database are indicated on the tree in the format TUBIACT. Ex-type sequences are highlighted in bold. Annulohypoxylon cohaerens and Hypoxylon rubiginosum were included as outgroups. 
Conidiogenous cells. Cylindrical, hyaline to brownish, smooth to finely roughened, (9.27-) 5.3 to $6.39(-3.64)$ (mean, 5.85) $\mu \mathrm{m}$ long and (3.08-) 2.49 to 2.69 (-1.90) (mean, 2.59) $\mu \mathrm{m}$ wide, bearing denticulate conidial secession scars on apical region.

Conidia. Produced holoblastically in sympodial sequence, hyaline, smooth, obovoid to clavate, (3.31-) 5.72 to $6.26(-8.23)$ (mean, 5.99) $\mu \mathrm{m}$ long and (1.66-) 2.17 to $2.32(-2.89)$ (mean, 2.25) $\mu \mathrm{m}$ wide, with flattened base indicating former point of attachment to conidiogenous cells.

Cultural characteristics. Colonies reaching a radius of $90 \mathrm{~mm}$ after 8 days at $25^{\circ} \mathrm{C}\left( \pm 2^{\circ} \mathrm{C}\right)$. Minimum temperature for growth, $7^{\circ} \mathrm{C}$; optimum, $25^{\circ} \mathrm{C}$; maximum, $39^{\circ} \mathrm{C}$. Colonies on MEA aerial, with entire margin; after 21 days, pale smoke gray $\left(21^{\prime \prime \prime \prime} f\right)$ to tawny-olive $\left(17^{\prime \prime} \mathrm{i}\right)$ above, argus brown $(13 \mathrm{~m})$ to verona brown $\left(13^{\prime \prime} \mathrm{k}\right)$ in reverse. Colonies on PDA aerial, with entire margin; after 21 days, deep olive buff $\left(21^{\prime \prime \prime} \mathrm{b}\right)$ to olive-buff $\left(21^{\prime \prime \prime} \mathrm{d}\right)$ above, buffy olive $\left(21^{\prime \prime} \mathrm{k}\right)$ to olive $\left(21^{\prime \prime} \mathrm{m}\right)$ in reverse. Colonies on OA aerial, with entire margin; after 21 days, avellaneous $\left(17^{\prime \prime \prime} \mathrm{b}\right)$ to olive $\left(21^{\prime \prime} \mathrm{m}\right)$ above, pale olive-buff $\left(21^{\prime \prime \prime} f\right)$ to black $(* 1)$ in reverse.
Substrate. Different species of Rosaceae, including Prunus domestica, Pyrus communis, and Cydonia oblonga.

Known distribution. Apulia, Italy.

Specimens examined. Italy, Apulia, Canosa di Puglia, on wood of Prunus domestica (Rosaceae), August 2013, Carlucci A. Bx26 (HOLOTYPE CBS H-22145 dried PDA colony, culture ex-type Bx26 = CBS 141046; ITS sequence KT253493, TUB sequence KT253527, ACT sequence KT253513, MycoBank MB816045.

Other specimen examined. Italy, Apulia, Canosa di Puglia, on wood of Cydonia oblonga (Rosaceae), September 2013, Carlucci A. Bx28 = CBS 141002; ITS sequence KT253490, TUB sequence KT253524, ACT sequence KT253510.

Notes. According to DNA sequence analysis, B. rosacearum is most closely related to $B$. mediterranea and $B$. atropunctata. This species, however, differs in several aspects from $B$. mediterranea and B. atropunctata. Asci and ascospores of B. rosacearum are smaller than $B$. mediterranea, and the conidiogenus structure is Nodulisporium-like. It differs from B. atropunctata on account of the mature stromatal surface, which is colored rather than white.
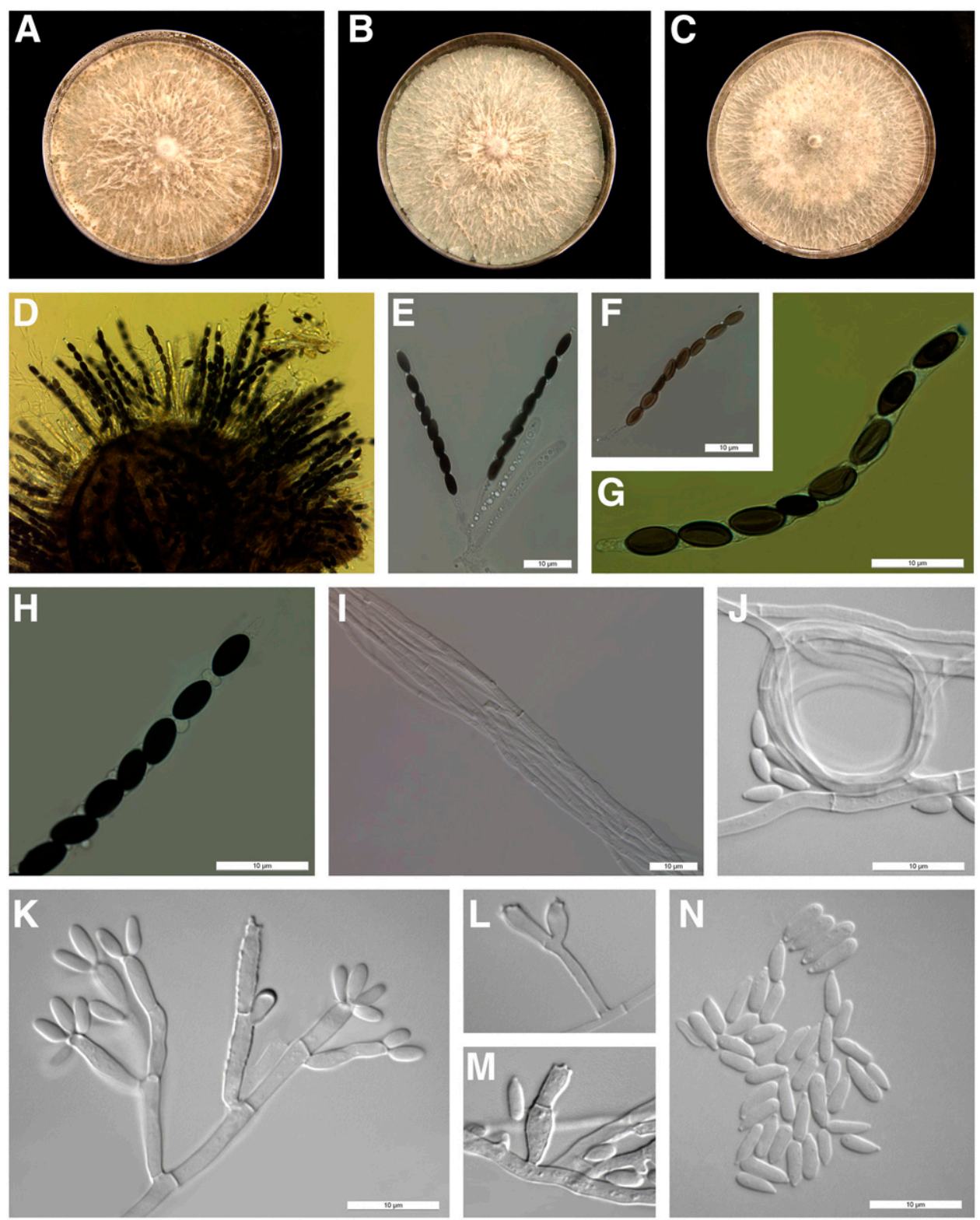

Fig. 4. Biscogniauxia rosacearum sp. nov. (Bx26 = CBS 141046). A to C, Sixteen-day-old colonies on $\mathbf{A}$, malt extract agar; $\mathbf{B}$, potato dextrose agar; and $\mathbf{C}$, oat meal agar at $25^{\circ} \mathrm{C}$. D, Asci in Lugol's reagent. E and F, Asci in 100\% acid lactic. G, Ascus with apical ring in Lugol's reagent, showing ascospores with germ slit. H, Ascum in $100 \%$ acid lactic showing oil contents. I, Mycelia in bundles of up to six. J, Hyphal coils. $\mathbf{K}$ to $\mathbf{M}$, Branched conidiophores and phialides. N, Conidia. 
Pathogenicity tests. The results of pathogenicity tests were all determined at 20 months after inoculations. All B. rosacearum isolates tested in the inoculation experiment produced three to five charcoal stromata on inoculated stems on all three of the hosts inoculated. Stroma diameter varied from 0.8 to $2 \mathrm{~cm}$. The inoculated stems produced poor vegetation, including flowers and fruit. According to the Shapiro-Wilk test, the data from the pathogenicity tests, on wood stems at 20 months after inoculation, followed a normal distribution (W $=0.77, P<0.00000$ ). The Levene test revealed that the homogeneity of variance was significant $(F=7.58, P<0.000000)$. Factorial ANOVA demonstrated that there were significant differences among hosts inoculated with $B$. rosacearum isolates $(F=$ $40.5, P<0.000000)$. The average percentages and standard deviations of artificially inoculated pear, plum, and quince stems showing stromata (by one-way ANOVA) are reported in Table 2. All B. rosacearum isolates produced stromata on stems, although with different percentages. Of the inoculated hosts, the most susceptible to $B$. rosacearum isolates was quince, of which all inoculated stems showed stromata on bark $(100 \%)$. Plum stems were less susceptible (ranging from 82 to $100 \%$ ) whereas pear stems were the most tolerant, with 78 to $92 \%$ showing stromata. No significant differences in aggressiveness were observed among the isolates used in the artificial inoculation, whereas all of the controls did not produce stromata. The fungi were always reisolated from all wood samples inoculated, regardless of whether they had produced the stromata, thus fulfilling Koch's postulate.

\section{Discussion}

This phylogenetic reconstruction based on ITS and TUB/ACT gene sequences has allowed us to distinguish a new species within the Biscogniauxia genus, as the here-described B. rosacearum. This is different from $B$. mediterranea because it is very well supported, as indicated in both of the phylogenetic trees. Also, the morphological features of $B$. rosacearum confirm that these are two different species because, although according to the molecular analyses it is more closely related to $B$. mediterranea, $B$. rosacearum has asci and ascospores that are smaller and its conidiogenus structure is Nodulisporiumlike, whereas $B$. mediterranea shows conidiogenus structures that are Periconiella-like, as defined by Ju and Rogers (1996).

Clade 1 of the ITS phylogenetic tree related to the new species here described for the first time, B. rosacearum, also includes 16 sequences named incorrectly as $B$. mediterranea from different hosts of European and Mediterranean Basin areas (Collado et al. 2001; Mirabolfathy et al. 2011; Sánchez Márquez et al. 2010; Trovão et al. 2013). Clade 2 appears to be correctly related to B. mediterranea species, because it includes five sequences from different hosts mainly from different states in the United States (Raja et al. 2015; Sánchez-Ballesteros et al. 2000; Silva-Hughes et al. 2015), one

Table 2. Pathogenicity tests carried out with four Biscogniauxia rosacearum isolates inoculated on pear, plum, and quince stems

\begin{tabular}{llcccc}
\hline $\begin{array}{l}\text { ID } \\
\text { isolate }\end{array}$ & Host & $\begin{array}{c}\text { Stem showing } \\
\text { stromata }(\boldsymbol{\%})^{\mathbf{x}}\end{array}$ & SD $^{\mathbf{y}}$ & Min-max $^{\mathbf{z}}$ & $\begin{array}{c}\text { Reisolation } \\
(\%)\end{array}$ \\
\hline Bx28 & Pear & 78 A & 7.9 & $70-90$ & 100 \\
Bx26 & Plum & $82 \mathrm{~A}$ & 6.3 & $70-90$ & 100 \\
Bx29 & Pear & 88 B & 4.2 & $80-90$ & 100 \\
Bx25 & Pear & 89 B & 5.7 & $80-100$ & 100 \\
Bx28 & Plum & 90 BC & 6.7 & $80-100$ & 100 \\
Bx26 & Pear & 92 BC & 6.3 & $80-100$ & 100 \\
Bx29 & Plum & 95 CD & 5.3 & $90-100$ & 100 \\
Bx26 & Quince & 100 D & 0 & $100-100$ & 100 \\
Bx29 & Quince & 100 D & 0 & $100-100$ & 100 \\
Bx25 & Plum & 100 D & 0 & $100-100$ & 100 \\
Bx25 & Quince & 100 D & 0 & $100-100$ & 100 \\
Bx28 & Quince & 100 D & 0 & $100-100$ & 100 \\
\hline
\end{tabular}

${ }^{x}$ Values followed by a different uppercase letter in each column are significantly different according to Fisher's test $(P<0.01)$.

y Standard deviation.

${ }^{\mathrm{z}}$ Minimum and maximum values detected on the basis of 10 observations. sequence (EF026134) from a European country (Hsieh et al. 2010), and five sequences from Italy collected in this study. Moreover, the sequence from France referred to a specimen examined by Ju et al. (1998) and given as B. mediterranea (Candoussau, F. 366). In particular, Collado et al. (2001) considered the fungal isolates indicated as two clades from their phylogenetic tree as sequences from two conspecific species, due to different geographic origins (i.e., Italy, Spain, Morocco, and the United States), although they claimed that the same clades were well distinguished and supported by high bootstrap values. Therefore, on the basis of morphological and phylogenetic features, we state that the two clades ( 1 and 2 ) do not relate to two conspecific species but, instead, to two different species of the genus Biscogniauxia.

The presence of charcoal stromata from fruit hosts such as pear, plum, and quince is very uncommon. In any case, on the basis of pathogenicity tests, it was possible to assess the ability of $B$. rosacearum isolates to infect pear, plum, and quince stems. On the other hand, in the older literature (Læssøe et al. 1999; Pouzar 1979; Vasilyeva 1988), some species of Biscogniauxia were related to some rosaceous hosts but no sequences of these are available from molecular data banks. B. mediterranea has never been isolated from rosaceous hosts, whereas $B$. pruni is reported from Prunus padus in Austria (Læssøe et al. 1999; Vasilyeva 1988), B. marginata from Malus communis (Pouzar 1979) in the Czech Republic, and B. granmoi from P. padus in Austria (Læssøe et al. 1999). No sequences reported in the phylogenetic tree of the present study are related to fungi from rosaceous hosts. Most Biscogniauxia spp. are associated with forest hosts, and mainly with Quercus spp. worldwide (De Sousa Santos 2003; Mirabolfathy et al. 2011; Ragazzi et al. 1989; Vannini and Scarascia Mugnozza 1991; Vannini et al. 1996). Moreover, we report that this fungus can cause severe damage to pear, plum, and quince trees, because it produced charcoal stromata when artificially inoculated under open-field conditions. Therefore, we strongly believe that this is a pathogen of rosaceous hosts, because this study is the first where $B$. rosacearum sp. nov. infects fruit hosts, although we also report for first time the occurrence of this novel Biscogniauxia spp. from $Q$. pubescens in southern Italy.

This putative adaptation or speciation of a species belonging to the Biscogniauxia genus to new plant hosts might have been influenced by unknown factors, which must be further investigated.

\section{Acknowledgments}

We thank G. Boccaccio for helpful assistance during field surveys and C. Ciccarone for helpful assistance with microphotographs of stromata. Some of the equipment used in this study was provided by Regione Puglia-Rete di Laboratori Pubblici SELGE. The present work was supported with a contribution on the funds of $5 \times 1000$ IRPEF in favor of the University of Foggia, in memory of Gianluca Montel.

\section{Literature Cited}

Biocca, M., and Motta, E. 1995. Aspects of latency of Hypoxylon mediterraneum in declining Turkey oaks (Quercus cerris). Petria 5:171-176.

Cannon, P. F., and Hawksworth, D. L., and Sherwood-Pike, M. A. 1985. The British Ascomycotina. An annotated checklist. Commonwealth Mycological Institute, Slough, UK.

Carbone, I., and Kohn, L. M. 1999. A method for designing primer sets for speciation studies in filamentous Ascomycetes. Mycologia 91:553-556.

Carlucci, A., Raimondo, M. L., Cibelli, F., Phillips, A. J. L., and Lops, F. 2013. Pleurostomophora richardsiae, Neofusicoccum parvum and Phaeoacremonium aleophilum associated with a decline of olives in southern Italy. Phytopathol. Mediterr. 52:517-527.

Carlucci, A., Raimondo, M. L., Santos, J., and Phillips, A. J. L. 2012. Plectosphaerella species associated with root and collar rots of horticultural crops in southern Italy. Persoonia 28:34-48.

Collado, J., Platas, G., and Pelaez, F. 2001. Identification of an endophytic Nodulisporium sp. from Quercus ilex in central Spain as the anamorph of Biscogniauxia mediterranea by rDNA sequence analysis and effect of different ecological factors on distribution of the fungus. Mycologia 93:875-886.

Crous, P. W., Gams, W., Stalpers, J. A., Robert, V., and Stegehuis, G. 2004 MycoBank: An online initiative to launch mycology into the 21st century. Stud. Mycol. 50:19-22.

Crous, P. W., Verkley, G. J. M., Groenewald, J. Z., and Samson, R. A. 2009 Fungal Biodiversity. CBS Laboratory Manual Ser. No. 1. CBS-KNAW Fungal Biodiversity Centre, Utrecht, The Netherlands. 
De Sousa Santos, M. N. 2003. Contribuicão para conhecimento das relacoes Quercus suber-Biscogniauxia mediterranea (syn. Hypoxylon mediterraneum). Silva Lusitana 11:21-29.

Desprez-Loustau, M. L., Marçais, B., Nageleisen, L. M., Piou, D., and Vannini, A. 2006. Interactive effects of drought and pathogens in forest trees. Ann. For. Sci. 63:597-612.

Fisher, P. J., Petrini, O., Petrini, L. E., and Descals, E. 1992. A preliminary study of fungi inhabiting xylem and whole stems of Olea europaea. Sydowia 44: $117-121$.

Glass, N. L., and Donaldson, G. C. 1995. Development of primer sets designed for use with the PCR to amplify conserved genes from filamentous infection due to Phaeoacremonium spp. J. Clin. Microbiol. 41:1332-1336.

Gonzàlez, F. S. M., and Rogers, J. D. 1993. Biscogniauxia and Camillea in Mexico. Mycotaxon 47:229-253.

Hsieh, H. M., Lin, C. R., Fang, M. J., Rogers, J. D., Fournier, J., Lechat, C., and Ju, Y.-M. 2010. Phylogenetic status of Xylaria subgenus Pseudoxylaria among taxa of the subfamily Xylarioideae (Xylariaceae) and phylogeny of the taxa involved in the subfamily. Mol. Phylogenet. Evol. 54:957-969.

Ju, Y.-M., and Rogers, J. D. 1996. A Revision of the Genus Hypoxylon. American Phytopathological Society, St. Paul, MN.

Ju, Y.-M., and Rogers, J. D. 2001. New and interesting Biscogniauxia taxa, with a key to the world species. Mycol. Res. 105:1123-1133.

Ju, Y.-M., Rogers, J. D., San Martìn Gonzalez, F., and Granmo, A. 1998. The genus Biscogniauxia. Mycotaxon 66:1-98.

Læssøe, T., Scheuer, C., and Granmo, A. 1999. Biscogniauxia granmoi (Xylariaceae) in Europe. Österr. Z. Pilzkd. 8:139-147.

Linaldeddu, B. T., Sirca, C., Spano, D., and Franceschini, A. 2011. Variation of endophytic cork oak associated fungal communities in relation to plant health and water stress. For. Pathol. 41:193-201.

Linnakoski, R., Puhakka-Tarvainen, H., and Pappinen, A. 2012. Endophytic fungi isolated from Khaya anthotheca in Ghana. Fungal Ecol. 5:298-308.

Miller, J. H. 1961. Page 158 in: A Monograph of the World Species of Hypoxylon. University of Georgia Press, Athens.

Mirabolfathy, M., Groenewald, J. Z., and Crous, P. W. 2011. The occurrence of charcoal disease caused by Biscogniauxia mediterranea on chestnut-leaved oak (Quercus castaneifolia) in the Golestan Forests of Iran. Plant Dis. 95:876.

Mugambi, G. K., Huhndorf, S. M., and Rogers, J. D. 2009. Two new xylariaceous species from Kenya. Mycotaxon 108:499-504.

Nugent, L. K., Sihanonth, P., Thienhirun, S., and Whalley, A. J. S. 2005. Biscogniauxia: A genus of latent invaders. Mycologist 19:40-43.

O’Donnell, K., and Cigelnik, E. 1997. Two divergent intragenomic rDNA ITS2 types within a monophyletic lineage of the fungus Fusarium are nonorthologous. Mol. Phylogenet. Evol. 7:103-116.

Page, R. D. 1996. TreeView: An application to display phylogenetic trees on personal computers. Comput. Appl. Biosci. 12:357-358.

Pažoutová, S., Srůtka, P., Holuša, J., Chudíčková, M., and Kolařík, M. 2010. The phylogenetic position of Obolarina dryophila (Xylariales). Mycol. Prog. 9: 501-507.

Peláez, F., González, V., Platas, G., Sánchez-Ballesteros, J., and Rubio, V. 2008. Molecular phylogenetic studies within the family Xylariaceae based on ribosomal DNA sequences. Fungal Divers. 31:111-134.

Pouzar, Z. 1979. Notes on taxonomy and nomenclature of Nummularia (Pyrenomycetes). Ceska Mykol. 33:207-219.

Pouzar, Z. 1986. A key and conspectus of central European species of Biscogniauxia and Obolarina (Pyrenomycetes). Ceska Mykol. 40:1-10.

Ragazzi, A. 2009. Espressione di malattia nell'endofitismo: da ipotesi a realtà. Micol. Ital. 38:29-46.

Ragazzi, A., Dellavalle Fedi, I., and Mesturino, L. 1989. The oak decline: A new problem in Italy. Eur. J. For. Pathol. 19:105-110.

Ragazzi, A., Ginetti, B., and Moricca, S. 2012. First report of Biscogniauxia mediterranea on English ash in Italy. Plant Dis. 96:1694.

Raimondo, M. L., Lops, F., and Carlucci, A. 2014. Phaeoacremonium italicum sp. nov., a new species associated with esca of grapevine in southern Italy. Mycologia 106:1119-1126.

Raja, H. A., Kaur, A., El-Elimat, T., Figueroa, M., Kumar, R., Deep, G., Agarwal, R., Faeth, S. H., Cech, N. B., and Oberlies, N. H. 2015. Phylogenetic and chemical diversity of fungal endophytes isolated from Silybum marianum (L) Gaertn. (milk thistle). Mycology 6:8-27.

Rappaz, F. 1995. Anthostomella and related xylariaceous fungi on hard wood from Europe and North America. Mycologia 7:99-168.

Rayner, R. W. 1970. A Mycological Colour Chart. Commonwealth Mycological Institute, Kew, Surrey, UK.

Rogers, J. D., San Martìn, F., Ju, Y.-M., and Hansen, K. 2000. Venezuelan fungi: Biscogniauxia viscosicentrica sp. nov. and the anamorph of Camillea cycolps. Nova Hedwigia 71:3-4.

Rogers, J. D., Vasilyeva, L. N., and Hay, F. O. 2008. New Xylariaceae from Hawaii and Texas (USA). Sydowia 60:277-286.

Sánchez-Ballesteros, J., Gonzalez, V., Salazar, O., Acero, J., Portal, M. A., Julian, M., Rubio, V., Bills, G. F., Polishook, J. D., Platas, G., Mochales, S., and Pelaez, F. 2000. Phylogenetic study of Hypoxylon and related genera based on ribosomal ITS sequences. Mycologia 92:964-977.

Sánchez Márquez, S., Bills, G. F., Domínguez Acuña, L., and Zabalgogeazcoa, I. 2010. Endophytic mycobiota of leaves and roots of the grass Holcus lanatus. Fungal Divers. 41:115-123.

Silva-Hughes, A. F., Wedge, D. E., Cantrell, C. L., Carvalho, C. R., Pan, Z., Moraes, R. M., Madoxx, V. L., and Rosa, L. H. 2015. Diversity and antifungal activity of the endophytic fungi associated with the native medicinal cactus Opuntia humifusa (Cactaceae) from the United States. Microbiol. Res. 175: 67-77.

Swofford, D. L. 2003. PAUP*. Phylogenetic Analysis Using Parsimony, Version 4. Sinauer Associates, Sunderland, MA.

Thompson, J. D., Gibson, T. J., Plewniak, F., Jeanmougin, F., and Higgins, D. G. 1997. The ClustalX windows interface: Flexible strategies for multiple sequence alignment aided by quality analysis tools. Nucleic Acids Res. 25: 4876-4882.

Trovão, J., Mesquita, N., Paiva, D. S., de Carvalho, H. P., Avelar, L., and Portugal, A. 2013. Can arthropods act as vectors of fungal dispersion in heritage collections? A case study on the archive of the University of Coimbra, Portugal. Int. Biodeterior. Biodegrad. 79:49-55.

Vannini, A., Biocca, M., and Paparatti, B. 1996. Contributo alla conoscenza de ciclo biologico di Hypoxylon mediterraneum (De Not.) Mill. su Quercus cerris. Inf. Fitopatol. 56:53-55.

Vannini, A., and Scarascia Mugnozza, G. 1991. Water stress: A predisposing factor in the pathogenesis of Hypoxylon mediterraneum on Quercus cerris. Eur. J. For. Pathol. 21:193-201.

Vasilyeva, L. N. 1988. The taxonomic position of Camarops polysperma (Mont.) J. H. Miller and Biscogniauxia Kuntze in the Far East. Mikol. Fitopatol. 22: 388-396.

Vasilyeva, L. N., and Stephenson, S. L. 2007. Cryptovalsaria gen. nov. and its two new species from eastern Asia and south central North America. Sydowia 59: 154-160.

Vasilyeva, L. N., and Stephenson, S. L. 2010. Biogeographical patterns in pyrenomycetous fungi and their taxonomy. 1. The Grayan disjunction. Mycotaxon 114:281-303.

Vasilyeva, L. N., Stephenson, S. L., Hyde, K. D., and Bahkali, A. H. 2012. Some stromatic pyrenomycetous fungi from northern Thailand-1. Biscogniauxia, Camillea and Hypoxylon (Xylariaceae). Fungal Divers. 55:65-76.

Whalley, A. J. S., Laessøe, T., and Kile, G. A. 1990. A new species of Biscogniauxia with appendaged ascospores from Tasmania. Mycol. Res. 94 237-239.

Whalley, A. J. S., Phosri, C., Ruchikachorn, N., Sihanonth, P., Sangvichien, E., Suwannasai, N., Thienhirun, S., and Whalley, M. A. 2012. Interesting or rare Xylariaceae from Thailand. Rajabhat J. Sci. Human. Soc. Sci. 13:9-19.

Whalley, M. A., Ju, Y.-M., Rogers, J. D., and Whalley, A. J. S. 2000. New xylariaceous fungi from Malaysia. Mycotaxon 74:135-140.

White, T. J., Bruns, T., Lee, S., and Taylor, J. 1990. Amplification and direct sequencing of fungal ribosomal RNA genes for phylogenetics. Pages 315-322 in: PCR Protocols, a Guide to Methods and Applications. M. A. Innis, D. H. Gelfand, J. J. Sninsky, and T. J. White, eds. Academic Press Inc., New York.

Wilson, D. 1995. Endophyte-The evolution of a term, and clarification of its use and definition. Oikos 73:274-276. 